\title{
The effect of melatonin on digoxin-induced cardiac damage in cardiomyocytes
}

\author{
Ovey IS ${ }^{1}$, Oncel $\mathrm{CR}^{2}$ \\ Department of Physiology, Alanya Alaaddin Keykubat University, School of Medicine, Alanya, Antalya, Turkey. \\ r_oncel@hotmail.com
}

\begin{abstract}
OBJECTIVES: Digoxin is a cardiac glycoside which is widely used in cardiovascular medicine. Oxidative stress, as well as intracellular $\mathrm{Ca}^{2+}$ overload, plays an important role in digoxin toxicity. Transient receptor potential vanilloid 1 (TRPV1) channels are found in cardiomyocyte cells and they are activated by reactive oxygen species. We investigated the effects of digoxin toxicity and alterations in $\mathrm{Ca}^{2+}$ influx, oxidative stress and apoptosis through TRPV1 channels and modulator role of melatonin in cardiomyocytes.

METHODS: The cells were divided into seven main groups as control, digoxin, digoxin+capsazepine, digoxin+melatonin, digoxin+capsazepine+melatonin, melatonin and melatonin+capsazepine groups. Cells in the groups were stimulated with capsaicin and inhibited with capsazepine in related experiments for activation and inactivation of TRPV1 channels, respectively. We measured cytosolic calcium, intracellular reactive oxygen, mitochondrial depolarization, caspase 9 and caspase 3 levels.

RESULTS: The apoptosis values were significantly lower in the melatonin and digoxin+melatonin groups than in the digoxin group of cardiomyocytes $(p<0.001)$. The cell viability values were higher in the digoxin+capsazepine $(p<0.001)$, digoxin+melatonin $(p<0.001)$ and digoxin+melatonin+capsazepine $(p<0.001)$ groups than in the digoxin group.

CONCLUSION: TRPV1 channels are overactivated during digoxin toxicity and melatonin could show a cardioprotective effect through TRPV1 channel modulation (Fig. 5, Ref. 56). Text in PDF www.elis.sk.
\end{abstract}

KEY WORDS: digoxin, oxidative stress, cardiomyocyte.

\section{Introduction}

Digoxin is a cardiac glycoside which is widely used in heart failure and atrial fibrillation patients as it increases inotropy and decreases chronotropy. It has multiple direct and indirect cardiovascular effects $(1,2)$. The inhibition of sarcolemma-bound $\mathrm{Na}^{+} /$ $\mathrm{K}^{+}$ATPase by digoxin leads to an increase in sodium $\left(\mathrm{Na}^{+}\right)$ion concentration. This cellular $\mathrm{Na}^{+}$overload causes an increase in free calcium $\left(\mathrm{Ca}^{2+}\right)$ concentration mediated by the $\mathrm{Na}^{+} / \mathrm{Ca}^{2+}$ exchanger. When cytoplasmic $\mathrm{Ca}^{2+}$ increases above the storage capacity of the sarcoplasmic reticulum, digoxin toxicity occurs $(3,4)$. Toxic concentrations of digoxin are associated with oxidation of membrane phospholipids and increase in lytic enzymes due to increase in intracellular $\mathrm{Ca}^{2+}(5-7)$.

Melatonin is an amphiphilic molecule which protects mitochondria against oxidative stress. It has been demonstrated that melatonin is a potent antioxidant, anti-apoptotic and anti-inflamma-

${ }^{1}$ Department of Physiology, Alanya Alaaddin Keykubat University, School of Medicine, Alanya, Antalya, Turkey, and ${ }^{2}$ Department of Cardiology, Alanya Alaaddin Keykubat University, School of Medicine, Alanya, Antalya, Turkey

Address for correspondence: C.R. Oncel, Alanya Alaaddin Keykubat University, School of Medicine, Department of Cardiology, Konya Çimento Street No: 80, Alanya/Antalya, Turkey. Zip Code: 07450

Phone: +905063715199 tory molecule which has protective effects in various organs including heart $(8,9)$. Vital role of transient receptor potential vanilloid 1 (TRPV1) channels in modulating heart failure, atherosclerotic heart disease and vascular remodeling has been shown in previous studies. Reactive oxygen species (ROS) activate and potentiate TRPV1 channels. Activating TRPV1 channels repeatedly is associated with increased cytosolic calcium levels, oxidative stress parameters and apoptosis levels $(10,11)$. Cardiomyocytes are one of main targets of ROS. Melatonin may modulate $\mathrm{Ca}^{2+}$ entry via TRPV1 and can affect oxidative stress parameters and cell injury in cardiomyocytes during digoxin toxicity.

To the best of our knowledge, there have been no previous reports on the roles of TRPV1 channels and melatonin during digoxin toxicity in cardiomyocytes. In the present study, we wanted to evaluate the effects of digoxin toxicity and alterations in $\mathrm{Ca}^{2+}$ influx, oxidative stress and apoptosis through TRPV1 channels and modulator role of melatonin in cardiomyocytes.

\section{Methods}

\section{Cell culture and reagents}

AC16 (Human cardiomyocyte cell line) was obtained from ATCC. Dulbecco's modified Eagle's medium (DMEM) (Sigma) was used for cardiomyocytes culture containing $12 \%$ fetal bovine serum (FBS) (Fisher Scientific, and $1 \%$ penicillin/streptomycin 
(Thermo-Fischer). Cardiomyocyte cells were evenly distributed as $1 \times 10^{6}$ cells in each of $8-10$ flasks (filter cap+sterile $+5 \mathrm{ml} ; 25$ $\mathrm{cm}^{2}$ ). A humidified incubator was used to incubate cardiomyocytes at $37{ }^{\circ} \mathrm{C}$ at $5 \% \mathrm{CO}_{2}$. After cells had reached $75-85 \%$ confluence, they were incubated with the chemical compounds described in groups section. Cells were examined daily for the evidence of contamination. After treatments, the cells were detached with $0.25 \%$ Trypsin-EDTA for analysis and split into the sterile falcon tubes for analyses.

Cell viability (MTT) dye was purchased from Thermo Fischer (Massachusetts, USA). Dihydrorhodamine-123 (DHR123) obtained from Molecular Probes (OR, USA). Caspase 3 and Caspase 9 substrates were purchased from Biovision (San Francisco, USA). APOPercentage dye with releasing buffer were obtained from Biocolor Ltd. (Northern Ireland), JC1 was purchased from Santa Cruz (Texas, USA), Fura 2 AM was purchased from Calbiochem (Darmstadt, Germany).

\section{Groups}

The study was planned with 7 main groups as follows,

Group 1 (Control): None of the study drugs were used and cardiomyocytes were kept in a flask containing the same cell culture condition.

Group 2 (DGX): Cardiomyocytes were incubated with $0.03 \mu \mathrm{M}$ digoxin for $30 \mathrm{~min}$ (12).

Group 3 (DGX+CAPZ): Cardiomyocytes were incubated with $0.03 \mu \mathrm{M}$ digoxin for $30 \mathrm{~min}$ and then incubated with capsazepin (CAPZ, $0.1 \mathrm{mM}, 30 \mathrm{~min}$ ).

Group 4 (DGX+Mel): Cardiomyocytes were incubated with 0.03 $\mu \mathrm{M}$ digoxin for $30 \mathrm{~min}$ and then incubated with $300 \mu \mathrm{M}$ melatonin for $2 \mathrm{~h}$.

Group 5 (DGX+Mel+CAPZ): Cardiomyocytes were incubated with $0.03 \mu \mathrm{M}$ Digoxin for $30 \mathrm{~min}$ and then incubated with $300 \mu \mathrm{M}$ melatonin for $2 \mathrm{~h}$ and then incubated with capsazepin (CAPZ, $0.1 \mathrm{mM}, 30 \mathrm{~min}$ ).

Group 6 (Mel): Cardiomyocytes were incubated with $300 \mu \mathrm{M}$ melatonin for periods of $2 \mathrm{~h}(13)$.

Group 7 (Mel+CAPZ): Cardiomyocytes were incubated with 300 $\mu \mathrm{M}$ melatonin for periods of $2 \mathrm{~h}$ and then incubated with capsazepin (CAPZ, $0.1 \mathrm{mM}, 30 \mathrm{~min}$ ).

In CAPZ incubated groups, cardiomyocytes were also blocked by TRPV1 blocker CAPZ $(0.1 \mathrm{mM}, 30 \mathrm{~min})$ prior to the related analysis in the existence of $1.2 \mathrm{mM}$ calcium in extracellular environment. For all experiments (except for calcium signaling), the cells were further treated with capsaicin (CPSN, $0.1 \mathrm{mM}, 10$ min) for activation of TRPV1 channel prior to the related analysis. During calcium signaling analysis (Fura-2/AM), the cells were stimulated on 20th cycles with $0.1 \mathrm{mM} \mathrm{CPSN}$ in the existence of $1.2 \mathrm{mM}$ calcium in extracellular environment.

\section{Measurements of intracellular calcium concentration}

UV light excitable Fura 2 AM (acetoxymethyl ester) dye was used for measuring intracellular calcium level in cardiomyocytes. The relevant experimental procedures were carried out in accor- dance with the experimental procedure of Uğuz et al, which included $4 \mu \mathrm{M}$ Fura 2 AM florescent dye for final staining period (14). Fluorescence emission intensity at $510 \mathrm{~nm}$ was determined in individual wells using a plate reader equipped with an automated injection system (SynergyTM H1, Biotek, USA) at alternating excitation wavelengths of 340 and $380 \mathrm{~nm}$ every $3 \mathrm{~s}$ for $50 \mathrm{ac}-$ quisition cycles. During the measurement of intracellular calcium signaling, TRPV1 channels were stimulated by automatic injector with capsaicin $(0.1 \mathrm{mM})$ on 20 th cycle. Measurement of $\mathrm{Ca}^{2+}$ analysis was performed as modified by Uguz et al, and Martinez et al, in previous studies $(14,15)$.

\section{Intracellular ROS production measurement}

DHR123 is a non-charged and non-fluorescent dye which easily goes through the cell membrane. The relevant experimental procedures were carried out in accordance with the experimental procedure of Espino et al (16). Inside the cardiomyocyte cell, DHR123 is oxidized to cationic rhodamine 123 (Rh 123) which localizes in the mitochondria and exhibits green fluorescence. Synergy ${ }^{\mathrm{TM}} \mathrm{H} 1$ automatic microplate reader device was used for determining Rh 123 fluorescent intensities. The analyses were performed at $488 \mathrm{~nm}$ (excitation) and $543 \mathrm{~nm}$ (emission) wavelengths. We presented the data as fold changes as from their levels before treatment.

\section{Apoptosis assay}

The APOPercentage ${ }^{\mathrm{TM}}$ cell apoptosis assay was used for the detection and quantification of apoptosis. The APOPercentage dye is actively bound to phosphatidyl-serine lipids and transferred into the cells, which stains apoptotic cells red. The apoptosis analyzes procedure was performed according to manufacturer's instruction and Özdemir et al (11). The cardiomyocytes were analyzed for apoptotic cells detection by spectrophotometry (multiplate reader) at $550 \mathrm{~nm}$ (Synergy ${ }^{\mathrm{TM}} \mathrm{H} 1$, Biotek, USA).

\section{Caspase 9 and caspase 3 activity assays}

Caspase 9 and Caspase 3 activity evaluation methods were based on previously reported studies $(17,18)$. Caspase 9 (ACLEHD-AMC) and Caspase 3 (ACDEVD-AMC) substrates cleavages were calculated with Synergy ${ }^{\mathrm{TM}} \mathrm{H} 1$ microplate reader (Biotek, USA) with $360 \mathrm{~nm}$ and $460 \mathrm{~nm}$ wavelengths (excitation/emission). The values were evaluated as fluorescent units/mg protein and shown as fold changes as from their levels before treatment (experimental/control).

\section{Mitochondrial membrane potential (JC1) analyses}

JC1 $(1 \mu \mathrm{M})$, which is a mitochondrial membrane potential fluorescence dye, was evaluated by $485 \mathrm{~nm}$ (green) excitation wavelength and emission wavelength of $535 \mathrm{~nm}$, red signal at $540 \mathrm{~nm}$ (excitation) and $590 \mathrm{~nm}$ (emission) wavelengths (Synergy $^{\mathrm{TM}} \mathrm{H} 1$, Biotek, USA). Data are presented as emission ratios (590/535). Mitochondrial membrane potential changes were quantified as the integral of the decrease in JC1 fluorescence ratio of experimental/control. 


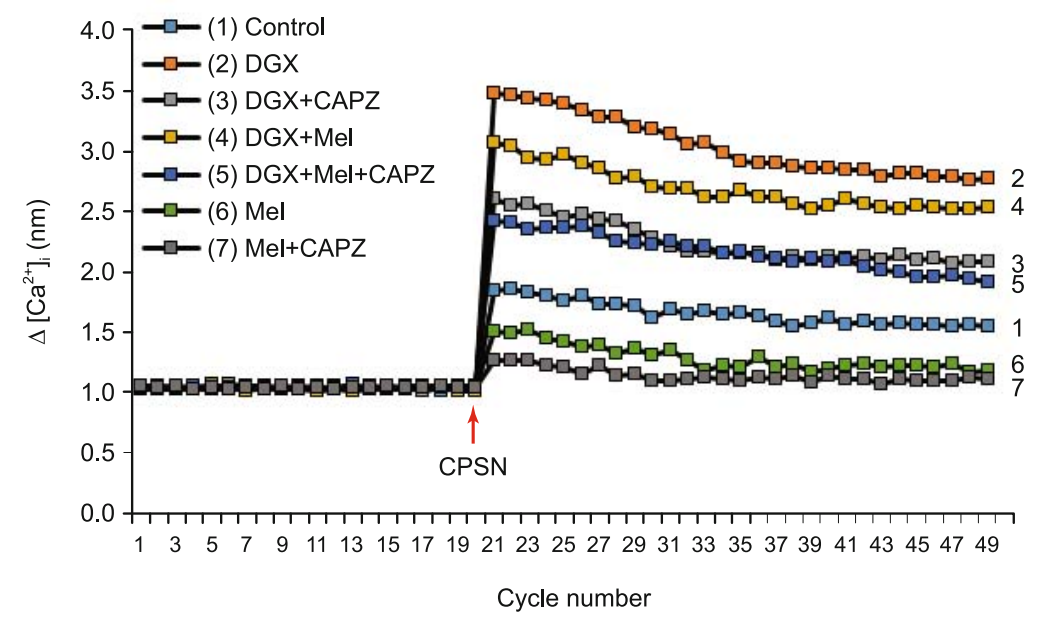

(B)

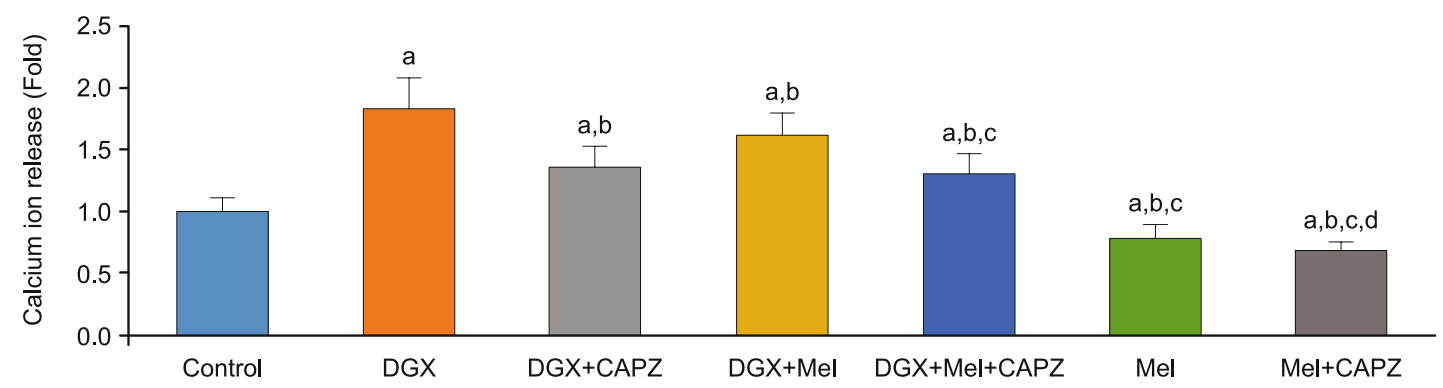

Fig. 1A, B. The effect of Digoxin ( $0.03 \mu \mathrm{M}$ for 30min) and Mel (300 $\mu \mathrm{M}$ for $2 \mathrm{hrs})$ on cytosolic calcium levels in cardiomyocyte cells. Cells are stimulated by capsaicin (CPSN $0.1 \mathrm{mM}$ and on 20th cycle) but blocked with capsazepine (CAPZ $0.1 \mathrm{mM}$ for $30 \mathrm{~min} ; \mathrm{mean} \pm \mathrm{SD}$ and $\mathrm{n}=10){ }^{\mathrm{a}} \mathrm{p}$ $<0.001$ vs control, ${ }^{\mathrm{b} p}<\mathbf{0 . 0 0 1}$ vs DGX, ${ }^{\mathrm{p}} \mathbf{2}<\mathbf{0 . 0 0 1}$ vs DGX+Mel and ${ }^{\mathrm{d} p}<0.001$ vs Mel. DGX: digoxin group, DGX+CAPZ: digoxin+capsazepine group, DGX+Mel: digoxin+melatonin group, DGX+Mel+CAPZ: digoxin+melatonin+capsazepine group, Mel: melatonin group, Mel+CAPZ: melatonin+capsazepine group.

\section{Cell viability (MTT) assay}

Cell viability was evaluated with MTT (3-(4,5-dimethylthiazol-2-yl)-2,5-diphenyltetrazolium bromide) assay. After treatments with chemical compounds as described in group section, the cardiomyocytes were washed and then incubated with fresh DMEM containing MTT $(0.5 \mathrm{mg} / \mathrm{ml})$ at $37^{\circ} \mathrm{C}$ for $90 \mathrm{~min}$ (19). Then, the supernatants were removed, and Dimethyl-sulfoxide was added to dissolve the formazan crystals. Optical density was estimated by Synergy ${ }^{\mathrm{TM}} \mathrm{H} 1$ automatic microplate reader device (Biotek, USA) at a test wavelength of $490 \mathrm{~nm}$ and reference wavelength of $650 \mathrm{~nm}$ to nullify the effect of cell debris. The obtained data are shown as fold changes as from their levels before treatment (experimental/control).

\section{Statistical analysis}

The values are presented as means \pm standard deviations (SD). To compare the different treatments, statistical significance was calculated by one-way analysis of variance (ANOVA) and MannWhitney U test. All data were analyzed by SPSS statistical program (version 9.05 software, SPSS Inc. Chicago, Illinois, USA) and p $<0.05$ was considered significant.

\section{Results}

Effects of digoxin toxicity and melatonin on cytosolic calcium levels in cardiomyocytes

The effect of digoxin toxicity and melatonin administrations on cytosolic calcium levels in cardiomyocyte cells are shown in Figure 1a, b. The TRP Vanilloid 1 channel blocker capsazepine was used to evaluate intracellular $\mathrm{Ca}^{2+}$ increase through TRPV1 channels in digoxin toxicity model of cardiomyocytes. As shown in Figure $1 \mathrm{~b}$, the $\mathrm{Ca}^{2+}$ concentration in cardiomyocytes was greater in the digoxin group when compared with the control $(\mathrm{p}<0.001)$. The $\mathrm{Ca}^{2+}$ level was lower in melatonin and melatonin+capsazepine groups than in the control $(\mathrm{p}<0.001)$. Also, cytosolic $\mathrm{Ca}^{2+}$ concentration was lower in the digoxin + capsazepine, digoxin + melatonin and digoxin + melatonin + capsazepine groups than in the digoxin group $(\mathrm{p}<0.001)$.

In addition, cytosolic $\mathrm{Ca}^{2+}$ concentration in the cardiomyocytes was markedly lower in the digoxin+melatonin+capsazepine group, compared to the digoxin+melatonin group $(\mathrm{p}<0.001)$. 


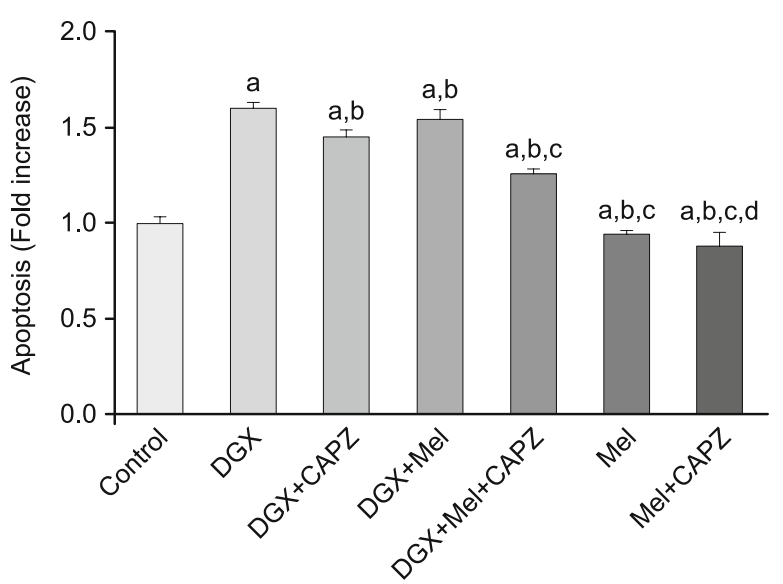

Fig. 2. The effect of Digoxin $(0.03 \mu \mathrm{M}, 30 \mathrm{~min})$ and Mel $(300 \mu \mathrm{M}, 2$ hrs) on apoptosis levels in the cardiomyocyte cells. Cells are stimulated by capsaicin (CPSN $0.1 \mathrm{mM}$ for $10 \mathrm{~min}$ ) but blocked with capsazepine (CAPZ $0.1 \mathrm{mM}$ for $30 \mathrm{~min}$; mean $\pm \mathrm{SD}$ and $\mathbf{n}=10){ }^{\mathrm{a}} \mathbf{p}<$ 0.001 vs control, ${ }^{\text {b }} p<0.001$ vs DGX, ${ }^{c} p<0.001$ vs DGX+Mel and ${ }^{\mathrm{d}} p<$ 0.001 vs Mel. DGX: digoxin group, DGX+CAPZ: digoxin+capsazepine group, DGX+Mel: digoxin+melatonin group, DGX+Mel+CAPZ: digoxin+melatonin+capsazepine group, Mel: melatonin group, Mel+CAPZ: melatonin+capsazepine group.

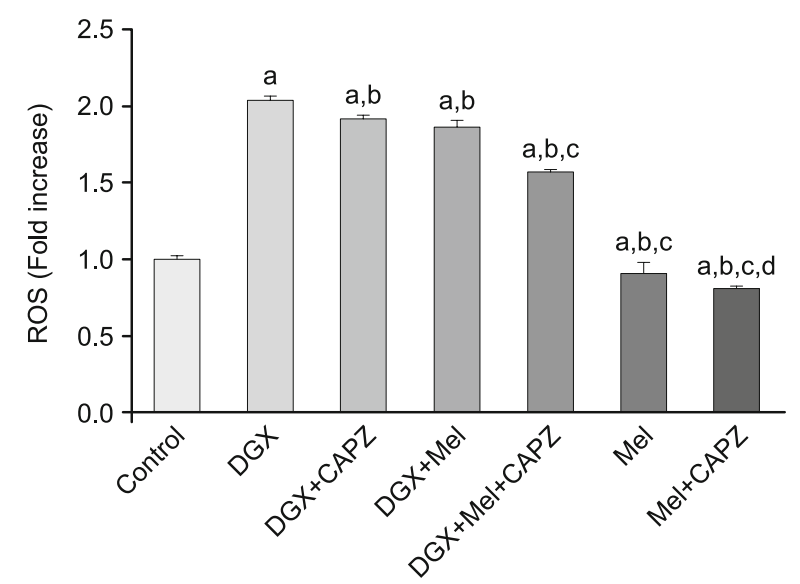

Fig. 3. The effect of Digoxin $(0.03 \mu \mathrm{M}, 30 \mathrm{~min})$ and Mel $(300 \mu \mathrm{M}, 2$ hrs) on reactive oxygen species (ROS) levels in the cardiomyocyte cells. Cells are stimulated by capsaicin (CPSN $0.1 \mathrm{mM}$ for $10 \mathrm{~min}$ ) but blocked with capsazepine (CAPZ $0.1 \mathrm{mM}$ for $30 \mathrm{~min}$; mean \pm

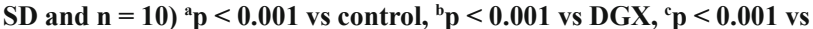
DGX+Mel and ${ }^{\mathrm{d}} \mathrm{p}<0.001$ vs Mel. DGX: digoxin group, DGX+CAPZ: digoxin+capsazepine group, DGX+Mel: digoxin+melatonin group, DGX+Mel+CAPZ: digoxin+melatonin+capsazepine group, Mel: melatonin group, Mel+CAPZ: melatonin+capsazepine group.

Effects of digoxin toxicity and melatonin on apoptosis levels in cardiomyocytes

Effects of digoxin toxicity and melatonin administrations on apoptosis levels are shown in Figure 2. The apoptosis values were higher in the digoxin group than in the control. The apoptosis values were lower in melatonin and digoxin+melatonin group than in the digoxin group of cardiomyocytes $(p<0.001)$. Also, the values were lower in the digoxin+melatonin+capsazepine group
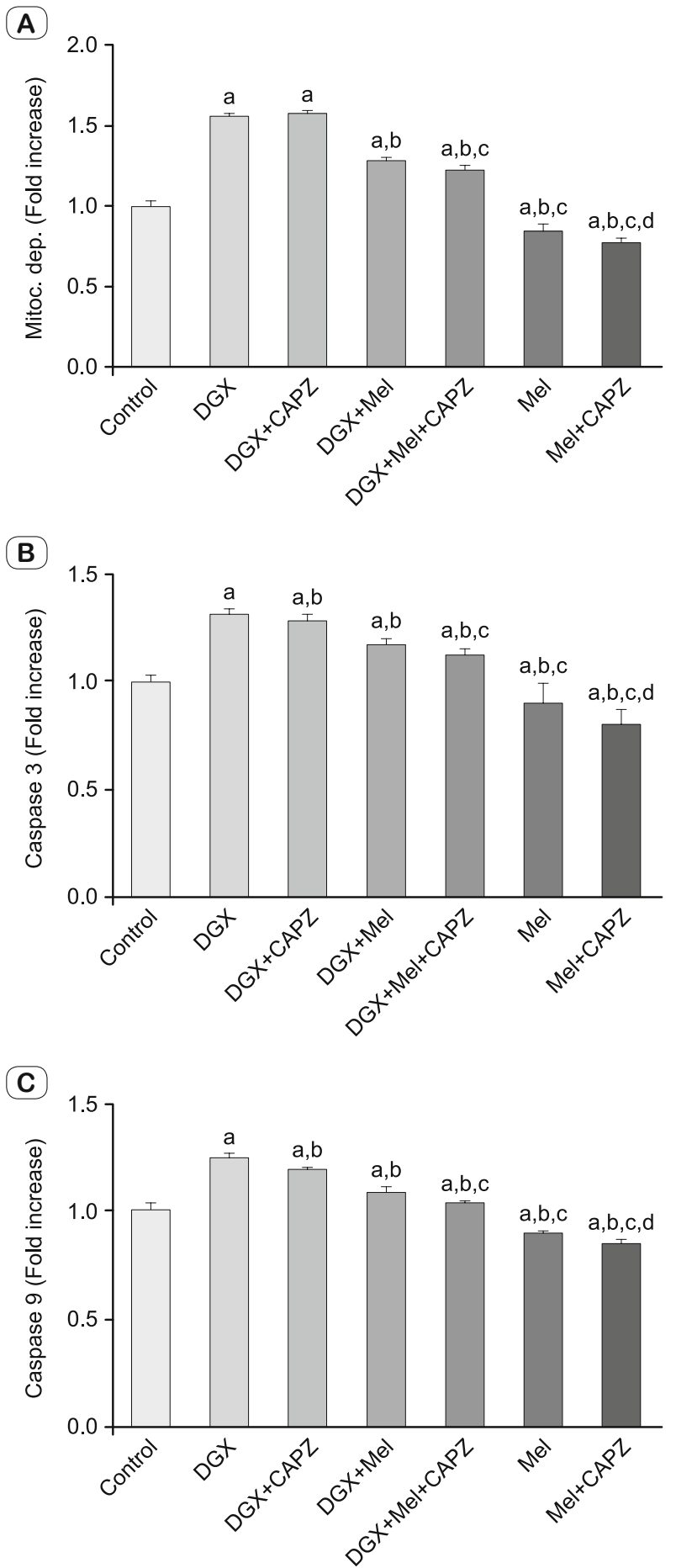

Fig. 4 A-C. The effect of Digoxin $(0.03 \mu \mathrm{M}, 30 \mathrm{~min})$ and $\mathrm{Mel}(300 \mu \mathrm{M}$, 2 hrs) on mitochondrial membrane depolarization (A), caspase 3 (B), caspase $9(\mathrm{C})$ levels in the cardiomyocyte cells. Cells are stimulated by capsaicin (CPSN $0.1 \mathrm{mM}$ for $10 \mathrm{~min}$ ) but blocked with capsazepine (CAPZ $0.1 \mathrm{mM}$ for $30 \mathrm{~min}$; mean $\pm \mathrm{SD}$ and $\mathbf{n}=10){ }^{\mathrm{a}} \mathrm{p}<0.001$ vs control, ${ }^{\mathrm{b}} \mathrm{p}<0.001$ vs DGX, ${ }^{\mathrm{c} p}<\mathbf{0 . 0 0 1}$ vs DGX+Mel and ${ }^{\mathrm{d}} \mathrm{p}<0.001$ vs Mel. DGX: digoxin group, DGX+CAPZ: digoxin+capsazepine group, DGX+Mel: digoxin+melatonin group, DGX+Mel+CAPZ: digoxin+melatonin+capsazepine group, Mel: melatonin group, Mel+CAPZ: melatonin+capsazepine group. 


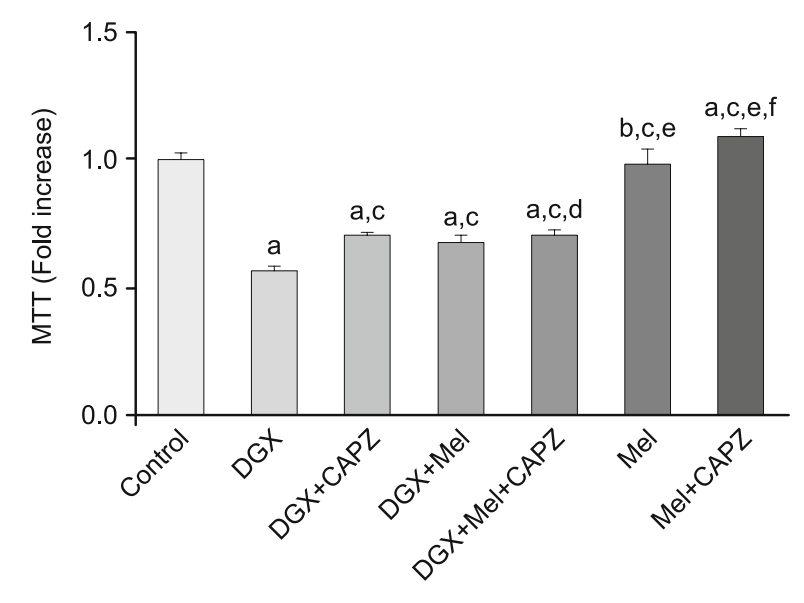

Fig. 5. The effect of Digoxin $(0.03 \mu \mathrm{M}, 30 \mathrm{~min})$ and Mel $(300 \mu \mathrm{M}, 2$ hrs) on MTT levels in the cardiomyocyte cells. Cells are stimulated by capsaicin (CPSN $0.1 \mathrm{mM}$ for $10 \mathrm{~min}$ ) but blocked with capsazepine (CAPZ $0.1 \mathrm{mM}$ for $30 \mathrm{~min}$; mean \pm SD and $\mathrm{n}=10)^{\mathrm{a}} \mathrm{p}<0.001$ and ${ }^{\mathrm{b}} \mathrm{p}<0.05$ vs control, ${ }^{\mathrm{c} p}<0.001$ vs DGX, ${ }^{\mathrm{d}} \mathrm{p}<0.05$ and ${ }^{\mathrm{e}} \mathrm{p}<0.001$ vs DGX+Mel and ${ }^{f} p<0.001$ vs Mel. DGX: digoxin group, DGX+CAPZ: digoxin+capsazepine group, DGX+Mel: digoxin+melatonin group, DGX+Mel+CAPZ: digoxin+melatonin+capsazepine group, Mel: melatonin group, Mel+CAPZ: melatonin+capsazepine group.

when compared with the digoxin + melatonin group of cardiomyocytes $(\mathrm{p}<0.001)$

Effects of digoxin toxicity and melatonin on intracellular ROS production in cardiomyocytes

Intracellular ROS production of groups are shown in Figure 3. The ROS production values of the digoxin group were greater than those in the control group. The values of digoxin + capsazepine $(p<0.001)$, digoxin + melatonin $(p<0.001)$ and digoxin + melatonin+capsazepine $(p<0.001)$ groups were lower than those in the digoxin group. Also, the ROS production was markedly lower in the digoxin+melatonin+capsazepine group when compared to the digoxin + melatonin group $(p<0.001)$.

Effects of digoxin toxicity and melatonin on caspase 3 and 9 activities, mitochondrial depolarization levels and cell viability (MTT) values in cardiomyocytes

Levels of mitochondrial membrane depolarization, caspase 3-9 activities of groups are shown in Figures 4 a, b, and c, respectively. It has been shown that caspase 3 and 9 activities have an important role in the mitochondrial apoptotic pathways. Also, they are associated with mitochondrial cytochrome $\mathrm{c}$ release during the apoptotic cascade $(20,21)$.

We showed the MTT values in Figure 5. Cell viability values in the digoxin group were lower than those in the control $(\mathrm{p}<0.001)$. The values were higher in the digoxin + capsazepine $(p<0.001)$, digoxin + melatonin $(p<0.001)$ and digoxin + melatonin + capsazepine $(\mathrm{p}<0.001)$ groups than in the digoxin group.

\section{Discussion}

Digital glycosides are used for patients with heart failure and arrhythmia worldwide, although excessive doses could cause cardiac adverse effects (22). Intracellular $\mathrm{Ca}^{2+}$ overload and oxidative stress play an important role in digoxin toxicity. It has been shown that digitalis-induced $\mathrm{Na}^{+}$accumulation causes an increase in $\mathrm{Ca}^{2+}$ through the $\mathrm{Na}^{+} / \mathrm{Ca}^{2+}$ exchanger. As a result of this internal $\mathrm{Ca}^{2+}$ overload, the net increase in intracellular $\mathrm{Ca}^{2+}$ activates further calcium release from the sarcoplasmic reticulum. The toxic effects have been seen when the sarcoplasmic reticulum storage capacity is exceeded. Intracellular $\mathrm{Ca}^{2+}$ overload is related to persistent inhibition of the $\mathrm{Na}^{+} / \mathrm{K}^{+}$ATPase and is associated with a rise in cell automaticity, impaired homeostasis and cell death. Adverse toxic effects are characterized by arrhythmia as well as apoptosis. Digitalis-induced arrhythmogenic effects are evaluated in previous studies but digitalis-induced apoptosis is not yet well understood $(23,24)$. In a study by Qubaassine et al, it has been shown that digoxin induced cell death in adult rat cardiomyocytes (25). Also, it has been described that toxic concentrations of digitalis cause a sustained elevation of internal $\mathrm{Ca}^{2+}$ levels that provoke apoptotic cell death (7).

Cardiac glycosides bind to $\mathrm{Na}^{+} / \mathrm{K}^{+}$ATPase and it opens the mitochondrial ATP-sensitive $\mathrm{K}^{+}$channel which leads to an increase in ROS. The reactive oxygen species are associated with inhibition of mitochondrial permeability transition which decreases myocyte viability. Cytochrome c release from mitochondria is a critical apoptotic event and this important event was induced by digoxin. Consistent with cytochrome c release induced by digoxin, is the activation of caspase 9 and caspase 3 . It is followed by proteolytic process with suggested oxidative stress-induced apoptosis (26-28).

Thus, we hypothesized that TRPV1 channels could be involved in glycoside-induced apoptosis. We think that the mechanism of digoxin to induce apoptotic cell death either in cultured cells or in live organism could follow a common pathway, in which $\mathrm{Ca}^{2+}$ plays a principal role. This intra cellular $\mathrm{Ca}^{2+}$ overload has been linked to mitochondrial dysfunction. We also think that digitalis-induced cell death is mainly apoptotic although a mixed mechanism of cell death cannot be ruled out.

In the current study, we showed that TRPV1 channels in cardiomyocytes are activated by digoxin administration. TRP channels are a family of unique ion channels which affect important cellular functions and signaling pathways. Also, they are primary targets for several potential drugs. They are known to play critical roles in cells' survival as well as their development. TRP channels can be divided into seven subfamilies as TRPC (canonical), TRPV (vanilloid), TRPM (melastatin), TRPP (polycystin), TRPML (mucolipin), TRPA (ankyrin), and TRPN (NOMPC) family (29, 30). They are activated by intracellular and extracellular messengers, chemical and mechanical stimuli and osmotic stress. Their main difference from voltage-dependent channels is that they are weakly sensitive to membrane potential. Some channels are activated by intracellular $\mathrm{Ca}^{2+}$ load whereas others are constitutively open $(31,32)$. Calcium has an important role as a second messenger in cardiac function including cardiac energy homeostasis, as well as 
cell death. Transient receptor potential (TRP) proteins are responsible for $\mathrm{Na}^{+}$and $\mathrm{Ca}^{2+}$ conducting channels which cause changes in the $\mathrm{Ca}^{2+}$ homeostasis and mediate longer lasting modulation of $\mathrm{Ca}^{2+}$ levels $(33,34)$. TRPV1, a member of vanilloid TRP family, is expressed in many organs including heart, kidney, brain, dorsal root ganglions and sensory neurons. It is a ligand-gated, homotetrameric, non-selective cation channel which is activated by heat (over $42{ }^{\circ} \mathrm{C}$ ), capsaicin (pungent substance from chili peppers) and low extracellular PH (35-37). Capsazepine is a competitive antagonist of capsaicin and it specifically blocks the TRPV1 channel (38). It has been demonstrated that TRPV1 channels are found in the ventricles of heart in the cardiovascular system and have an important role in modulating cardiovascular diseases including atherosclerosis, congestive heart failure and systemic hypertension (39-42). Authors have reported that activation of TRPV1 channels could aggravate heart failure $(43,44)$. Also, it has been shown that the toxicity of digoxin was amplified in congestive heart failure as a consequence of $\mathrm{Na}^{+} / \mathrm{Ca}^{2+}$ exchanger upregulation (45). Furthermore, previous studies have demonstrated that activation of TRPV1 channels have a dual role in the progression of heart failure (42).

Although oxidative stress has an important role in digoxin toxicity, its role in TRPV1 channel activation has not been investigated yet. Dai et al, showed that extracellular ROS activated TRPV1 channels in apoptosis which is induced by hypoxia in hippocampal neurons (46). Also, authors of previous studies evaluated the role of TRPV1 channel activation in oxidative stress, apoptotic cell injury, and increased cytosolic free $\mathrm{Ca}^{2+}$. Chuang et al demonstrated that TRPV1 channel activation by capsaicin was increased in oxidative stress (47). Similarly, Hu et al, showed that increased intracellular $\mathrm{Ca}^{2+}$ entry and activation of NADPH oxidase was associated with TRPV1-induced oxidative stress. On the other hand, oxidative stress causes activation of ion channels by phosphorylation and this process is involved in $\mathrm{Ca}^{2+}$ influx through TRPV1 channels (48). We observed that digoxin toxicity increased oxidative stress, intracellular $\mathrm{Ca}^{2+}$ entry and apoptosis in cardiomyocytes. In the current study we showed that intracellular ROS production and $\mathrm{Ca}^{2+}$ levels were increased through TRPV1 channel activation by digoxin toxicity and capsaicin stimulation in cardiomyocytes.

Also, we demonstrated that melatonin reduced ROS, apoptosis, and $\mathrm{Ca}^{2+}$ entry through modulation of TRPV1. Melatonin is a pineal secretory product, strong antioxidant and an anti-apoptotic molecule which can pass through all cellular compartments easily $(49,50)$. It participates in the antioxidant and anti-apoptotic processes directly or indirectly. Melatonin has protective effects in many organs including heart, brain and liver (51-53). Furthermore, protective effects of melatonin during oxidative stress and apoptosis have been shown before in previous studies (8). Moreover, it has been demonstrated that it decreased the effectiveness of voltage-operated $\mathrm{Ca}^{2+}$ channels and induced the $\mathrm{Ca}^{2+}$-dependent ATPase in cardiac sarcolemma (54). In addition, the protective effect of melatonin in reperfusion arrhythmias has been reported previously and melatonin was suggested to be used as an adjunct therapy in myocardial infarction (55). In a study by Kahya et al, the effect of melatonin on oxidative stress parameters, apoptosis levels and intracellular calcium entry via TRPV1 channels in dia- betic rats has been evaluated. They found that the modulation of this channel by melatonin involves neuroprotective activities in diabetic rats (56). In the present study, we observed that melatonin could influence intracellular homeostasis during digoxin toxicity. We found that melatonin administration has beneficial effects on apoptosis levels and intracellular ROS production during digoxin toxicity in cardiomyocytes.

\section{Study limitations}

Mainly, we did not evaluate the concentration response to distinguish effects of therapeutic versus toxic levels of digoxin on the molecular mechanism studied in the present study. Also, we could not perform an electrophysiological study and evaluate whether digoxin toxicity changes also the expression of TRPV1 channels in cardiomyocytes.

\section{Conclusion}

In conclusion, we showed that TRPV1 channels are overactivated by ROS and mediate the lethal cytosolic $\mathrm{Ca}^{2+}$ increase in digoxin toxicity. Melatonin could show a cardioprotective effect through TRPV1 channel modulation in cardiomyocytes.

\section{References}

1. Ambrosy AP, Butler J, Ahmed A, Vaduganathan M, van Veldhuisen DJ, Colucci WS et al. The use of digoxin in patients with worsening chronic heart failure: reconsidering an old drug to reduce hospital admissions. J Am Coll Cardiol 2014; 63: 1823-1832.

2. Fuster V, Ryden LE, Cannom DS, Crijns HJ, Curtis AB, Ellenbogen KA et al. ACC/AHA/ESC 2006 guidelines for the management of patients with atrial fibrillation: a report of the American College of Cardiology/American Heart Association Task Force on practice guidelines and the European Society of Cardiology Committee for Practice Guidelines (Writing Committee to Revise the 2001 guidelines for the management of patients with atrial fibrillation): developed in collaboration with the European Heart Rhythm Association and the Heart Rhythm Society. Circulation 2006; 114: e257-354.

3. Gonano LA, Sepúlveda M, Rico Y, Kaetzel M, Valverde CA, Dedman $\mathbf{J}$ et al. Calcium-calmodulin kinase II mediates digitalis-induced arrhythmias. Circ Arrhythm Electrophysiol 2011; 4: 947-57.

4. Skou JC. The energy coupled exchange of $\mathrm{Na}+$ for $\mathrm{K}+$ across the cell membrane. The $\mathrm{Na}^{+}, \mathrm{K}^{+}$-pump. FEBS Lett 1990; 268: 314-324.

5. McConkey DJ, Lin Y, Nutt LK, Ozel HZ, Newman RA. Cardiac glycosides stimulate $\mathrm{Ca} 2+$ increases and apoptosis in androgen-independent, metastatic human prostate adenocarcinoma cells. Cancer Res 2000; 60: 3807-3812.

6. Ramirez Ortega M, Maldonado Lagunas V, Melendez Zajgla J, Carrillo Hernandez JF, Pastelín Hernandez G, Picazo Picazo O et al. Proliferation and apoptosis of HeLa cells induced by in vitro stimulation with digitalis. Eur J Pharmacol 2006; 534: 71-76.

7. Ramirez Ortega M, Zarco G, Maldonado V, Carrillo JF, Ramos P, Ceballos $\mathbf{G}$ et al. Is digitalis compound-induced cardiotoxicity, mediated through guinea pig cardiomyocytes apoptosis? Eur J Pharmacol 2007; 566: 34-42. 
8. Asghari MH, Abdollahi M, de Oliveira MR, Nabavi SM. A review of the protective role of melatonin during phosphine-induced cardiotoxicity: focus on mitochondrial dysfunction, oxidative stress and apoptosis. J Pharm Pharmacol 2017; 69: 236-243.

9. Vazan R, Ravingerova T. Protective effect of melatonin against myocardial injury induced by epinephrine. J Physiol Biochem 2015; 71: 43-49.

10. Crouzin N, Ferreira MC, Cohen-Solal C, Barbanel G, Guiramand J, Vignes M. Neuroprotection induced by vitamin $\mathrm{E}$ against oxidative stress in hippocampal neurons: involvement of TRPV1 channels. Mol Nutr Food Res 2010; 54: 496-505.

11. Özdemir ÜS, Nazıroğlu M, Şenol N, Ghazizadeh V. Hypericum perforatum attenuates spinal cord injury induced oxidative stress and apoptosis in the dorsal root ganglion of rats: involvement of TRPM2 and TRPV1 channels. Mol Neurobiol 2016; 53: 3540-3551.

12. Watanabe H, Honda Y, Deguchi J, Yamada T, Bando K. Usefulness of cardiotoxicity assessment using calcium transient in human induced pluripotent stem cell-derived cardiomyocytes. J Toxicol Sci 2017; 42: 519-527.

13. Celik O, Nazıroğlu M. Melatonin modulates apoptosis and TRPM2 channels in transfected cells activated by oxidative stress. Physiol Behav 2012; 107: 458-465.

14. Uguz AC, Naziroglu M, Espino $J$ et al. Selenium modulates oxidative stress-induced cell apoptosis in human myeloid HL-60 cells through regulation of calcium release and caspase-3 and -9 activities. J Membr Biol 2009; 232: 15-23.

15. Martinez NA, Ayala AM, Martinez M, Martinez-Rivera FJ, Miranda JD, Silva WL. Caveolin-1 regulates the P2Y2 receptor signaling in human 1321N1 astrocytomacells. J Biol, Chem 2016; 291: 12208-

16. Espino J, Pariente JA, Rodríguez AB. Role of melatonin on diabetesrelated metabolic disorders. World J Diabetes 2011; 2: 82-91.

17. Bejarano I, Redondo PC, Espino J, Rosado JA, Paredes SD, Barriga $\mathrm{C}$ et al. Melatonin induces mitochondrial-mediated apoptosis in human myeloid HL-60 cells. J Pineal Res 2009; 46: 392-400.

18. Espino J, Bejarano I, Redondo PC, Rosado JA, Barriga C, Reiter RJ et al. Melatonin reduces apoptosis induced by calcium signaling in human leukocytes: Evidence for the involvement of mitochondria and Bax activation. J Membr Biol .2010; 233: 105-118.

19. Övey IS, Naziroğlu M. Homocysteine and cytosolic GSH depletion induce apoptosis and oxidative toxicity through cytosolic calcium overload in the hippocampus of aged mice: involvement of TRPM2 and TRPV1 channels. Neuroscience 2015; 284: 225-233.

20. Shi Y. Apoptosome: the cellular engine for the activation of caspase-9. Structure 2002; 10: 285-288

21. Li P, Nijhawan D, Budihardjo I, Srinivasula SM, Ahmad M, Alnemri ES et al. Cytochrome c and dATP-dependent formation of Apaf-1/ caspase-9 complex initiates an apoptotic protease cascade. Cell 1997; 91: 479-489.

22. Bauman JL, Didomenico RJ, Galanter WL. Mechanisms, manifestations, and management of digoxin toxicity in the modern era. Am J Cardiovasc Drugs 2006; 6: 77-86.

23. Olej B, dos Santo NF, Leal L, Rumjanek VM. Ouabain induces apoptosis on PHA-activated lymphocytes. Biosci Rep.1998; 18: 1-7.

24. Yeh JY, Huang WJ, Kan SF, Wang PS. Inhibitory effects of digitalis on the proliferation of androgen dependent and independent prostate cancer cells. J Urol 2001; 166: 1937-1942.
25. Oubaassine R, Weckering M, Kessler L, Breidert M, Roegel JC, Eftekhari P. Insulin interacts directly with $\mathrm{Na}^{+} / \mathrm{K}^{+} \mathrm{ATPase}$ and protects from digoxin toxicity. Toxicology 2012; 299: 1-9.

26. Wieckowski, M, Vyssokikh M, Dymkowska D, Antonsson B, Brdiezka D, Wojtczak L. Oligomeric c-terminal truncated Bax preferentially releases cytochrome $\mathrm{c}$ but not adenylate kinase from mitochondria, outer membrane vesicles and proteoliposomes. FEBS Lett 2001; 505: 453-459.

27. Ekert PG, Read SH, Silke J, Marsden VS, Kaufmann H, Hawkins CJ et al. Apaf-1 and caspase-9 accelerate apoptosis, but do not determine whether factor-deprived or drug-treated cells die. J. Cell Biol 2004; 165 : 835-842.

28. Ishida, H, Hirota Y, Genka C, Nakazawa H, Nakaya H, Sato T. Opening of mitochondrial K (ATP) channels attenuates the ouabain-induced calcium overload in mitochondria. Circ Res 2001; 89: 856-858.

29. Nilius B, Owsianik G. The transient receptor potential family of ion channels. Genome Biol 2011; 12: 218

30. Kaneko Y, Szallasi A. Transient receptor potential (TRP) channels: a clinical perspective. Br J Pharmacol 2014; 171: 2474-2507.

31. Venkatachalam K, Montell C. TRP channels. Annu Rev Biochem 2007; 76: 387-417.

32. Jie Zheng. Molecular Mechanism of TRP Channels. Compr Physiol 2013; 3: 221-42.

33. Flockerzi V, Nilius B. TRPs: truly remarkable proteins. Handb Exp Pharmacol 2014; 222: 1-12.

34. Bers DM. Calcium cycling and signaling in cardiac myocytes. Annu Rev Physiol 2008; 70: 23-49.

35. Gao F, Liang Y, Wang X, Lu Z, Li L, Zhu S et al. TRPV1 activation attenuates high-salt diet-induced cardiac hypertrophy and fibrosis through PPAR- $\delta$ upregulation, PPAR Res 2014; 2014: 491963.

36. Kassmann M, Harteneck C, Zhu Z, Nürnberg B, Tepel M, Gollasch M. Transient receptor potential vanilloid 1 (TRPV1), TRPV4, and the kidney. Acta Physiol (Oxford) 2013; 207: 546-564.

37. Khatibi NH, Jadhav V, Charles S, Chiu J, Buchholz J, Tang J et al. Capsaicin pre-treatment provides neurovascular protection against neonatal hypoxic-ischemic brain injury in rats. Acta Neurochir Suppl 2011; 111: 225-230.

38. van den Worm E, de Vries A, Nijkamp FP, Engels F. Capsazepine, a vanilloid receptor antagonist, inhibits allergen-induced tracheal contraction. Eur J Pharmacol 2005; 518: 77-78.

39. Li L, Wang F, Wei X, Liang Y, Cui Y, Gao F et al. Transient receptor potential vanilloid 1 activation by dietary capsaicin promotes urinary sodium excretion by inhibiting epithelial sodium channel $\alpha$ subunit-mediated sodium reabsorption, Hypertension 2014; 64: 397-404.

40. Lang H, Li Q, Yu H, Li P, Lu Z, Xiong S,et al. Activation of TRPV1 attenuates high salt-induced cardiac hypertrophy through improvement of mitochondrial function.Br J Pharmacol 2015; 172: 5548-5558.

41. Li BH, Yin YW, Liu Y, Pi Y, Guo L, Cao XJ et al. TRPV1 activation impedes foam cell formation by inducing autophagy in oxLDL-treated vascular smooth muscle cells. Cell Death Dis 2014; 5: e1182.

42. Randhawa PK, Jaggi AS. TRPV1 channels in cardiovascular system: A double edged sword? Int J Cardiol 2017; 228: 103-113.

43. Lu S, Xu D. Cold stress accentuates pressure overload-induced cardiac hypertrophy and contractile dysfunction: role ofTRPV1/AMPK-mediated autophagy, Biochem Biophys Res Commun 2013; 442: 8-15. 
44. Thilo F, Liu Y, Schulz N, Gergs U, Neumann J, Loddenkemper $\mathbf{C}$ et al. Increased transient receptor potential vanilloid type 1 (TRPV1) channel expression in hypertrophic heart. Biochem Biophys Res Commun 2010; 401: 98-103.

45. Gaughan JP, Furukawa S, Jeevanandam V, Hefner CA, Kubo H, Margulies KB et al. Sodium/ calcium exchange contributes to contraction and relaxation in failed human ventricular myocytes. Am J Physiol 1999; 277: H714-724.

46. Dai Z, Xiao J, Liu SY, Cui L, Hu GY, Jiang DJ. Rutaecarpine inhibits hypoxia/reoxygenation-induced apoptosis in rat hippocampal neurons. Neuropharmacology 2008; 55: 1307-1312.

47. Chuang HH, Lin S. Oxidative challenges sensitize the capsaicin receptor by covalent cysteine modification. Proc Natl Acad Sci USA 2009; 106: 20097-20102.

48. Hu F, Sun WW, Zhao XT, Cui ZJ, Yang WX. TRPV1 mediates cell death in rat synovial fibroblasts through calcium entry-dependent ROS production and mitochondrial depolarization. Biochem Biophys Res Commun 2008; 369: 989-993.

49. Reiter RJ, Garcia JJ, Pie J. Oxidative toxicity in models of neurodegeneration: responses to melatonin. Restor Neurol Neurosci 1998; 12: $135-142$.

50. Baydas G, Reiter RJ, Akbulut M, Tuzcu M, Tamer S. Melatonin inhibits neural apoptosis induced by homocysteine in hippocampus of rats via inhibition of cytochrome $\mathrm{c}$ translocation and caspase-3 activation and by regulating pro-and anti-apoptotic protein levels. Neuroscience 2015; 135: 879-886.
51. Vazan R, Ravingerova T. Protective effect of melatonin against myocardial injury induced by epinephrine. J Physiol Biochem .2015; 71: 43-49.

52. Kireev R, Bitoun S, Cuesta S, Tejerina A, Ibarrola C, Moreno E et al. Melatonin treatment protects liver of Zucker rats after ischemia/reperfusion by diminishing oxidative stress and apoptosis. Eur J Pharmacol 2013; 701: 185-193.

53. Kilic U, Yilmaz B, Ugur M, Yüksel A, Reiter RJ, Hermann DM et al. Evidence that membrane-bound $\mathrm{G}$ protein-coupled melatonin receptors MT1 and MT2 are not involved in the neuroprotective effects of melatonin in focal cerebral ischemia. J Pineal Res 2012; 52: 228-235.

54. Diez ER, Prados LV, Carrión A, Ponce ZA, Miatello RM. A novel electrophysiologic effect of melatonin on ischemia/reperfusion-induced arrhythmias in isolated rat hearts. J Pineal Res 2009; 46: 155-160.

55. Dominguez-Rodriguez A, Abreu-Gonzalez P, Garcia-Gonzalez MJ, Kaski JC, Reiter RJ, Jimenez-Sosa A. A unicenter, randomized, doubleblind, parallel-group, placebo-controlled study of Melatonin as an Adjunct in patients with acute myocaRdial Infarction under-going primary Angioplasty The Melatonin Adjunct in the acute myocaRdial Infarction treated with Angioplasty (MARIA) trial: study design and rationale. Contemp Clin Trials 2007; 28: 532-539.

56. Kahya MC, Nazıroğlu M, Övey IS. Modulation of Diabetes-Induced Oxidative Stress, Apoptosis, and Ca2+ Entry Through TRPM2 and TRPV1 Channels in Dorsal Root Ganglion and Hippocampus of Diabetic Rats by Melatonin and Selenium. Mol Neurobiol 2017; 54: 2345-2360.

Received September 23, 2018. Accepted November 5, 2018. 